\title{
Onset of Sexual Maturity in Female Chickens is Genetically Linked to Loci Associated with Fecundity and a Sexual Ornament
}

\author{
Dominic Wright, C Rubin, K Schutz, S Kerje, A Kindmark, H Brandstrom, \\ L Andersson, T Pizzari and Per Jensen
}

\section{Linköping University Post Print}

N.B.: When citing this work, cite the original article.

This is the pre-reviewed version of the following article:

Dominic Wright, C Rubin, K Schutz, S Kerje, A Kindmark, H Brandstrom, L Andersson, T Pizzari and Per Jensen, Onset of Sexual Maturity in Female Chickens is Genetically Linked to Loci Associated with Fecundity and a Sexual Ornament, 2012, Reproduction in domestic animals (1990), (47), SI, 31-36.

which has been published in final form at:

http://dx.doi.org/10.1111/j.1439-0531.2011.01963.x

Copyright: Blackwell Publishing

http://www.blackwellpublishing.com/

Postprint available at: Linköping University Electronic Press

http://urn.kb.se/resolve?urn=urn:nbn:se:liu:diva-74154 
Linköping, Sweden

ONSET OF SEXUAL MATURITY IN FEMALE CHICKENS IS GENETICALLY

LINKED TO LOCI ASSOCIATED WITH FECUNDITY AND A SEXUAL

ORNAMENT

Wright, D. ${ }^{1}$, Rubin, C. ${ }^{2}$, Schutz, K. ${ }^{3}$, Kerje, S. ${ }^{2}$, Kindmark, A. ${ }^{4}$, Brandström, H. ${ }^{4}$, Andersson, L. ${ }^{2}$, Pizzari, T. ${ }^{5}$, Jensen, P. ${ }^{1}$

${ }^{1}$ IFM Biology, AVIAN Behaviour Genomics and Physiology Group, Linköping University, Linköping SE-58183

${ }^{2}$ Dept of Medical Biochemistry and Microbiology, Uppsala University, Uppsala SE-75124

${ }^{3}$ AgResearch Ltd, Private Bag 3123, Hamilton 3240, New Zealand

${ }^{4}$ Department of Medical Sciences, Uppsala University Hospital, Uppsala, SE-751 85

${ }^{5}$ Edward Grey Institute, Department of Zoology, University of Oxford, South Parks Road, Oxford OX1 3PS, United Kingdom

Running title: Linkage between onset of sexual maturity and a sexual ornament in the chicken 


\section{ABSTRACT}

Onset of sexual maturation is a trait of extreme importance both evolutionarily and economically. Unsurprisingly therefore, domestication has acted to reduce the time to sexual maturation in a variety of animals, including the chicken. In comparison to wild progenitor chickens (the Red Junglefowl), domestic layer hens attain maturity approximately $20 \%$ earlier. In addition, domestic layers also possess larger combs (a sexual ornament), produce more eggs and have denser bones. A large Quantitative Trait Loci (QTL) analysis $(n=377)$ was performed using an $\mathrm{F}_{2}$ intercross between a White Leghorn layer breed and a Red Junglefowl population, with onset of sexual maturity measured and mapped to three separate loci. This cross has already been analysed for comb mass, egg production and bone allocation. Onset of sexual maturity significantly correlated with comb mass, whilst the genetic architecture for sexual maturity and comb mass overlapped at all three loci. For two of these loci the QTL for sexual maturity and comb mass were statistically indistinguishable from pleiotropy, suggesting that the alleles that increase comb mass also decrease onset of sexual maturity. 


\section{INTRODUCTION}

Sexual maturation and its onset signals the start of an animals reproductive life and is a trait of profound importance from both an evolutionary and economic perspective. The earlier the onset of maturation, the greater the total potential offspring production, and hence commensurate gains in fitness (Hulet et al. 1969). It is therefore of no great surprise that the domestication process has served to decrease the time taken to reach sexual maturation, with examples in numerous different animals (including chicken (Etches 1996), sheep (Tchernov and Horwitz 1991), dogs (Morey 1994)). In the chicken for example, females of domestic breeds can reach maturation approximately $20 \%$ earlier than their wild counterparts (Schutz et al. 2002).

Sexual maturation itself has been shown to be under strong hormonal control, and in the case of chickens maturation has been shown to be associated with increased levels of estradiol 17beta. Hormones affect a variety of other traits in the chicken, including secondary sexual characteristics. In the chicken this is principally the comb (Joseph et al. 2003), with the comb indicating mate quality in both males and females, and used to base mating decisions on (Pizzari and Birkhead 2000, Pizzari et al. 2003, Wright et al. 2008, Zuk et al. 1990). The role of hormonal control of this system is also shown by birds that have had a thyroidectomy performed on them having both decreased comb size and delayed onset of sexual maturity. When such birds are given hormonal thyroid replacement, both comb size increases and onset of lay commences (Greenwood and Chu. 1939). The link with comb size is particularly interesting in the chicken, with comb size in chickens associated with intense sexual selection. In a study using a wild-derived Red Junglefowl population (RJF, with low egg production and small comb size) crossed with a domestic White Leghorn (WL, with high egg 
production and large comb size) layer population it has been shown that female comb size is correlated with number of eggs produced and total egg output (Wright et al. 2008). Genetic regions (in the form of quantitative trait loci, QTL) for both fecundity and comb size map to similar chromosomal regions. These colocalised 'blocks' may represent groups of linked genes, though in some cases they may also be a single gene exhibiting pleiotropic effects (where one allele affects two or more traits) (Wright et al. 2008). Given the link between sexual maturity and comb size (see above), the potential for a hormonal regulation of both comb size and sexual maturity could point to a pleiotropic mechanism affecting both.

In turn, bone metabolism has also been shown to be linked with egg production. Bone metabolism is particularly relevant for egg production in the chicken due to the limiting nature of calcium availability for egg shell production (Reynolds et al. 2004). During periods of egg production calcium is transferred from the hard outer cortical bone to the endosteal cavity as trabecular and medullary bone (Dacke et al. 1993), which is then utilised for eggshell production (Cransberg et al. 2001). This process is mediated by estrogen, which decreases the number of osteoclasts present on the endosteal surface (Kusuhara and Schraer 1982). At a genetic level the architecture for comb mass and bone mass once again appear to be either linked or pleiotropic (Wright et al. 2008). Given the role estrogen plays in comb size, and the link between comb size and egg production, the link between onset of sexual maturity and bone allocation also requires further clarification.

To investigate this, onset of sexual maturity in females was assessed in a Red Junglefowl (RJF) x White Leghorn (WL) $\mathrm{F}_{2}$ intercross which had previously been 
assayed for comb size and various bone and fecundity morphological measures (see Wright et al. 2008). As well as showing differences in comb size and egg production, these two parental populations also show large differences in onset of sexual maturation, with female WL attaining maturation at a mean age of 19.9 weeks (s.d. 1.5), whereas RJF females reach sexual maturation at a mean age of 24.9 weeks (s.d. 2.7) (Schutz et al. 2002). This allowed phenotypic analysis of sexual maturity with comb, egg and bone traits, as well as allowing a QTL analysis of onset of sexual maturity to be performed to identify genetic regions associated with differential onset of sexual maturity between the two breeds.

\section{MATERIALS AND METHODS}

\section{Study population.}

Two parental populations of chickens were used in this study, a White Leghorn (WL) line artificially selected for increased egg mass production (SLU13) and a red junglefowl (RJF) population, the wild progenitor of the domestic chicken. Additional details of these two populations are presented in (Schutz et al. 2002). An intercross was generated by crossing three WL females with one RJF male. A total of $811 \mathrm{~F}_{2}$ progeny were generated from the $F_{1}$ population, with these animals reared in six batches between May-December 1999 and raised under standardised conditions at the research station of the Swedish University of Agricultural Sciences, Skara.

\section{Phenotypic measurements.}


Onset of sexual maturity was ascertained by palpating the cloaca of each female once per week. The females were considered sexually mature when an approximate $2.5 \mathrm{~cm}$ gap was observed between the left and right Tuber ischii. Comb size was measured by weighing the mass of the comb after post-mortem surgical removal, and was conducted on $474 \mathrm{~F}_{2}$ birds (122 females, 352 males). Reproductive investment was measured by collecting the eggs for one week at 29 weeks of age, during which time the birds were kept individually in standard laying cages. Number of eggs, total weight of eggs for the period and mean egg weight were all recorded. Egg data was available from $377 \mathrm{~F}_{2}$ females. Individuals that produced no eggs during the reproduction assay were excluded from the phenotypic and QTL analysis of fecundity, due to potential outlier effects and their low output being possibly due to health or problems unrelated to actual reproductive output. Bodyweight was measured immediately post-mortem at 230 days of age. A total of 37 different measures of bone density, strength and composition were also taken post-mortem in $333 \mathrm{~F}_{2}$ birds (159 females, 172 males), and 20 parental birds, using both the left and right femoral bones of each bird. These are outlined in further detail in (Rubin et al. 2007). These 37 measurements were reduced down to seven for the analysis. Three measures were used as recorded, whilst the bulk were condensed down into four principal components. Of the individual traits, DXA bone mineral density, DXA bone mineral content and endosteal circumference were used, whilst a total of four other principal component analyses (PCA) were calculated for cortical bone, diaphyseal and metaphyseal medullary bone density, diaphyseal and metaphyseal medullary area and femoral characteristics. The cortical bone PCA was derived from cortical content, density, area and thickness, with the first axis explaining $81 \%$ of the present variation. The femoral PCA was derived from DXA bone mineral density and content measures 
from the femur, as well as femoral area and length, with the first axis explaining $72 \%$ of the total variation. The medullary bone area PCA, composed of metaphyseal medullary area, bone mineral content and diaphyseal medullary bone area, explained $60 \%$ of the variation present. The medullary bone density PCA comprising of the metaphyseal medullary bone mineral density and diaphyseal medullary bone mineral density measures, explained $62 \%$ of the variation present. Of the 122 females for which comb mass was measured, 102 were also phenotyped for bone traits, and of the 352 males for which comb mass was measured, 173 were also phenotyped for bone traits. See table 1 for a list of phenotype means and standard deviations in the parental populations used.

Genotyping and statistical analysis.

DNA was extracted using a standard salt extraction kit from whole blood (see (Kerje et al. 2003)), with a total of 160 molecular markers used, covering 29 autosomes and the $\mathrm{Z}$ chromosome. Total map coverage was $3356 \mathrm{cM}$, with an average interval distance of $21 \mathrm{cM}$. A full list of markers used is presented in (Wright et al. 2006). QTL analysis consisted of interval mapping, with batch and sex being included as fixed effects, whilst bodyweight at 200 days was included as a covariate. Analysis was performed using QTLexpress (Seaton et al. 2002). Correlations were performed using a General Linear Model in SPSS v10.1. Batch number was included as a factor, whilst body mass was included as an additional covariate. Due to non-normality, a boot-strapping procedure with 1000 replicates was used to establish significance thresholds, with the R statistical software (v2.2) used for this purpose. 
Pleiotropy analysis was performed using a multivariate analysis in the package qxpak version 2.16 (Perez-Enciso and Misztal 2004). Traits on each chromosome were taken pairwise, with the likelihood for two QTL explaining the traits (so one QTL per trait) tested against the likelihood for one QTL explaining both traits (one QTL for both traits), using a Likelihood Ratio test with one degree of freedom.

\section{RESULTS}

Phenotypic architecture

Onset of sexual maturity was found to be a significant predictor of several bone morphological traits as well as comb size. Sexual maturity was a significant positive predictor of overall DXA bone mineral content $(\mathrm{F}=7.2, \mathrm{P}=0.008, \mathrm{~B}=0.7$, with bodyweight $(\mathrm{F}=41.0, \mathrm{P}=0.001)$ also controlled for in the model, total $\mathrm{r}$-squared of the model $=0.29$, see fig $1 . A)$ and overall DXA bone mineral density $(\mathrm{F}=5.1, \mathrm{P}=0.03$, $\mathrm{B}=0.003$, bodyweight $\mathrm{F}=16.8, \mathrm{P}=0.001$, total $\mathrm{r}$-squared $=0.14$ ). Sexual maturity was also a significant predictor of total egg production $(\mathrm{F}=11.2, \mathrm{P}=0.001, \mathrm{~B}=-4,0,384$ d.f., bodyweight $\mathrm{F}=58,6, \mathrm{P}=0.001$, total $\mathrm{r}$-squared=0.18, see fig $1 . \mathrm{B}$ ) and egg number $(\mathrm{F}=12.5, \mathrm{P}=0.001, \mathrm{~B}=-0.08,384$ d.f., bodyweight $\mathrm{F}=8.2, \mathrm{P}=0.004$, total $\mathrm{r}$-squared $=$ 0.07), but not mean egg weight $(\mathrm{F}=0.001, \mathrm{P}=0.97)$.

Comb size was a significant predictor of sexual maturity $(F=6,4, P=0.01, B=-$ 4.3, r-squared=0.06, see fig1.C), bodyweight was strongly non-significant in the subsample of birds with both sexual maturity and comb size measures $(\mathrm{F}=0.3, \mathrm{P}=0.6)$ and was therefore removed. In the full sample, body weight was also not a significant 
predictor of sexual maturity, though in this case this effect was less pronounced $\mathrm{F}=2.5, \mathrm{P}=0.1$, d.f. $=390$.

\section{Genetic Architecture}

The genetic architecture of comb size in this cross has been analysed previously (Wright et al. 2008), as has the genetic architecture of bone allocation and fecundity (Rubin et al. 2007, Wright et al. 2008), therefore this analysis comprised solely of the analysis of onset of sexual maturity, a female-specific trait. Previous comb size QTL had been found on chromosomes 1, 3 and 8 . In the current analysis, two suggestive and one significant onset of sexual maturity QTL were identified, two on chromosome 1 (at $97 \mathrm{cM}$ and 232cM, see fig.2) and one on chromosome 3 (at $84 \mathrm{cM}$, see fig.3). All of these QTL were located close to a comb size QTL. In the case of chromosome 1, two comb QTL are found at $87 \mathrm{cM}$ and $193 \mathrm{cM}$, whilst on chromosome 3 a comb QTL is located at $66 \mathrm{cM}$ (see table 2).

The direction of effect of the detected sexual maturity QTL was transgressive in the case of the two QTL on chromosome 1, i.e. the RJF allele actually caused a slight decrease in the time of onset of sexual maturity, whilst the direction of effect was as expected for the chromosome 3 QTL. Interestingly, this precisely mirrors the direction of effects seen for the comb size QTL. In those, the two on chromosome 1 are also transgressively segregating, with the QTL on chromosome 3 showing greater effects (i.e a decrease in time to onset of sexual maturity) from the White Leghorn allele. Therefore all of the onset of sexual maturity QTL are located close to a comb size QTL, and in all cases an increase in comb size is mirrored by a decrease in the time of onset of sexual maturity. 
To explore whether these comb and sexual maturity QTL represented single pleiotropic units or linked but separate loci, a multivariate test was performed fitting either two QTL or one QTL models (see table 3). In the case of the sexual maturity and comb size QTL on chromosome 1 at 87 and $97 \mathrm{cM}$, and the two loci on chromosome 3, despite both linkage models having a higher likelihood these were statistically indistinguishable from the pleiotropy model (chromosome $1 \mathrm{~F}=1.9$, $\mathrm{P}=0.16$, chromosome $3 \mathrm{~F}=2.6, \mathrm{P}=0.11$ ). Only in the case of the QTL at $232 \mathrm{cM}$ on chromosome 1 was linkage found to be statistically significant over pleiotropy $(\mathrm{F}=7.5$, $\mathrm{P}=0.01$ ). However, in this instance both the comb and sexual maturity QTL were only relatively weakly significant (at the suggestive level of significance).

Previously, comb size QTL were shown to be linked with QTL for bone allocation and fecundity on chromosome 1 (Wright et al. 2008). For the region on chromosome 1 containing the onset of sexual maturity QTL at $84 \mathrm{cM}$, it is linked with the bone allocation QTL, rather than potentially pleiotropic, whilst the comb QTL located there $(87 \mathrm{cM})$ is also linked rather than pleiotropic with the trabecular BMD and total egg production QTL further upstream on the chromosome. In the case of the onset of sexual maturity QTL on chromosome 3, this is indistinguishable from closelinkage/ pleiotropy with the QTL for bone allocation (DXA bmd) and fecundity (mean egg weight).

\section{DISCUSSION}

Onset of sexual maturity is correlated with comb, fecundity and bone phenotypes, whilst also shares either a common genetic basis or is linked with the genes for these other traits. Onset of sexual maturity is either tightly linked or pleiotropic (the 
resolution of this experiment is insufficient to separate the loci if they are linked, but this cannot be ruled out) to two of the three comb loci. The third loci (on chromosome 1 at $232 \mathrm{cM}$ ) is only suggestively significant, as is the comb size QTL, so the lower power here may preclude the accurate positioning of the locus and prevent an accurate determination of potential pleiotropy. Despite this caveat, the direction of effects of the onset of sexual maturity QTL alleles precisely mirror those for comb size, so when an allele in an QTL causes an increase in comb size in the domestic line, this is mirrored by an allele in an adjacent QTL causing a decrease in time of onset of sexual maturation in the domestic line. Similarly, when the allele at the QTL causes an increase in comb size in the wild line, the adjacent QTL will show a decrease in time of onset of sexual maturity in the wild line. Given the links that have been observed between hormone levels and comb size, the data presented here would indicate that comb size and onset of sexual maturity share a pleiotropic link, with alleles causing an increase in comb size also causing a decrease in time of sexual maturation.

It has been shown previously in this cross that comb QTL are located in 'blocks' of linked comb mass, bone allocation and fecundity QTL (Wright et al. 2008). These blocks may have a pleiotropic core, but many of the QTL are actually in linkage with each other, rather than pleiotropic. This is particularly true of the block for bone allocation, fecundity and comb size on chromosome 1. Given the pleiotropy between comb size and onset of sexual maturity, it is unsurprising that the onset of sexual maturity QTL are linked with, rather than pleiotropic to, QTL for fecundity and bone allocation on chromosome 1 (as is the case with these QTL and the QTL for comb size). The loci on chromosome 3 for onset of sexual maturation, bone allocation, comb size and fecundity however are all either pleiotropic or sufficiently tightly linked to be unable to distinguish between the two. Generally though, the 
linkage blocks found in these studies point to linked modules, surrounding a pleiotropic core. The implications of the linkage blocks in this case could support the theory of the genome being organised into groups of functionally related clusters (Larkin et al. 2009). This has been shown for strongly conserved and basic structures (limb bud development, etc (Carroll et al. 2005)), though in this instance the clusters would represent more diverse traits.

Calcium mobilisation and medullary bone formation are induced by both oestrogen and androgen, and aryl hydrocarbon (dioxin) receptors are highly expressed in medullary bone. Comb expression is also steroid-dependent (Bullock and Hall 1968, Parker et al. 1942). Despite this, the data presented here on chromosome 1 suggest that the loci controlling variation in the bone and fecundity traits are distinct from the locus or loci controlling comb size and onset of sexual maturity. This suggests that whilst onset of sexual maturity and comb size variation may share a similar genetic basis, they are part of a wider linked network of genes affecting the whole system.

\section{ACKNOWLEDGEMENTS}

The Study was funded by the Foundation for Strategic Environmental Research, the Swedish Research Council for Environmental, Agricultural Sciences and Spatial Planning, and the Swedish Research Council. 
Females

Males

\begin{tabular}{|c|c|c|c|c|}
\hline Trait & RJF & WL & RJF & WL \\
\hline Comb mass $(\mathrm{g})$ & $1.1 \pm 0.3$ & $7.3 \pm 0.6$ & & \\
\hline Sexual maturity (wk) & $24.9 \pm 2.7$ & $19.9 \pm 1.5$ & & \\
\hline Egg number (no./wk) & $2.6 \pm 2.3$ & $6.0 \pm 1.7$ & & \\
\hline Mean egg mass $(\mathrm{g})$ & $23 \pm 19.8$ & $57.5 \pm 15.2$ & & \\
\hline Total egg mass (g/wk) & $97.3 \pm 96.6$ & $367.1 \pm 109.6$ & & \\
\hline $\mathrm{DXA} B M C(\mathrm{mg} / \mathrm{mm})$ & $35 \pm 8$ & $72 \pm 19$ & $56 \pm 6$ & $71 \pm 3$ \\
\hline DXA BMD $(\mathrm{mg} / \mathrm{cm} 3)$ & $331 \pm 34$ & $467 \pm 78$ & $376 \pm 20$ & $389 \pm 40$ \\
\hline $\begin{array}{l}\text { Body weight at } 200 \text { days } \\
\text { (g) }\end{array}$ & $799.5 \pm 130.1$ & $1629.3 \pm 110.4$ & $1119.1 \pm 136.3$ & $2107.2 \pm 148.3$ \\
\hline
\end{tabular}

Table 1. Means and standard deviations for traits used in the parental populations. 
Table 2. QTL for onset of female sexual maturity and comb mass in a red junglefowl $x$ domestic F2 cross. Positive additive effects indicate greater effects in red junglefowl alleles, negative indicate greater effects in domestic (White Leghorn) alleles.

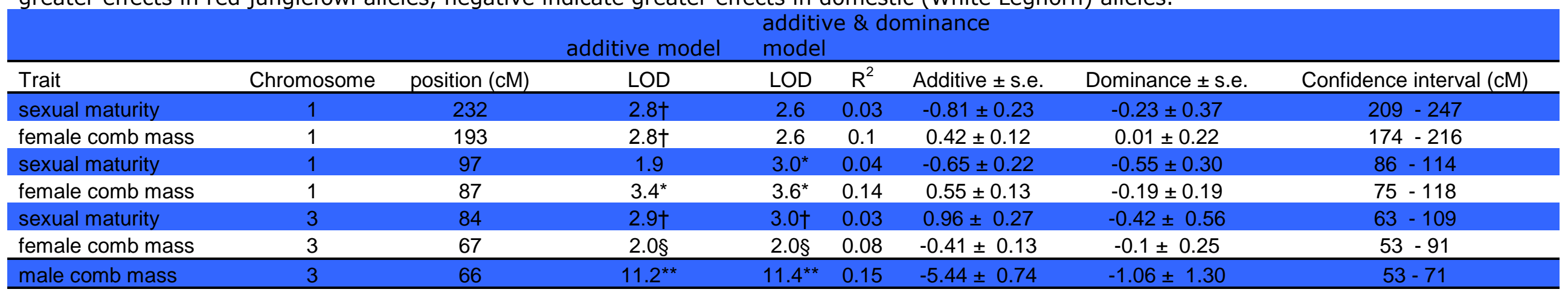

Confidence interval is calculated by the region indicated by a one-Lod drop of the highest Lod score. $\dagger$ suggestive at the $20 \%$ genome-wide level of significance, ${ }^{*}$

significant at the $5 \%$ genome-wide level of significance, ${ }^{* *}$ significant at the $1 \%$ genome-wide level of significance, $\S$ significant at the $1 \%$ single position level of

significance. 


\begin{tabular}{|c|c|c|c|}
\hline Pairwise traits & $\begin{array}{l}\text { Pleiotropic vs } \\
\text { linkage }\end{array}$ & LR & p-value \\
\hline \multicolumn{4}{|l|}{ chromosome 1} \\
\hline female comb mass vs time to sexual maturity & linkage & 1.9 & 0.16 \\
\hline trabecular bmd vs time to sexual maturity & linkage & 8.9 & $0.00 * * *$ \\
\hline female comb mass vs time to sexual maturity $(232 \mathrm{cM})$ & linkage & 7.5 & $0.01 *$ \\
\hline \multicolumn{4}{|l|}{ chromosome 3} \\
\hline comb mass vs time to sexual maturity & linkage & 2.6 & 0.11 \\
\hline egg mean weight vs time to sexual maturity & linkage & 0.5 & 0.48 \\
\hline DXA bmd vs time to sexual maturity & linkage & 2.5 & 0.11 \\
\hline
\end{tabular}

Table 3. Pairwise likelihood ratio tests for linkage vs pleiotropy for onset of sexual maturity and comb mass, bone allocation and fecundity QTL. 
Figure 1. Graph showing correlation between onset of sexual maturity and (A) DXA bone mineral content, (B) total egg production for one week and (C) comb mass corrected for body weight for the $\mathrm{F}_{2}$ chickens used in the study.

Figure 2. QTL for onset of sexual maturity, comb mass, reproductive and skeletal quality on Chromosome 1. The y-axis covers a subset of the total chromosomal length (50-240cM from the total length of $498 \mathrm{cM})$, the $\mathrm{x}$-axis represents percentage of population mean. QTL effects are expressed as percentage of the population mean. Effects greater in the Red Junglefowl direction (red) are negative, whilst those for the domestic line (blue) are positive. Error bars indicate the QTL confidence interval as defined by a drop in LOD score by 1 .

Figure 3. QTL for onset of sexual maturity, comb mass, reproductive and skeletal quality on Chromosome 1. The y-axis covers a subset of the total chromosomal length (40-120cM from the total length of $335 \mathrm{cM})$. All other notes as for figure 2. 


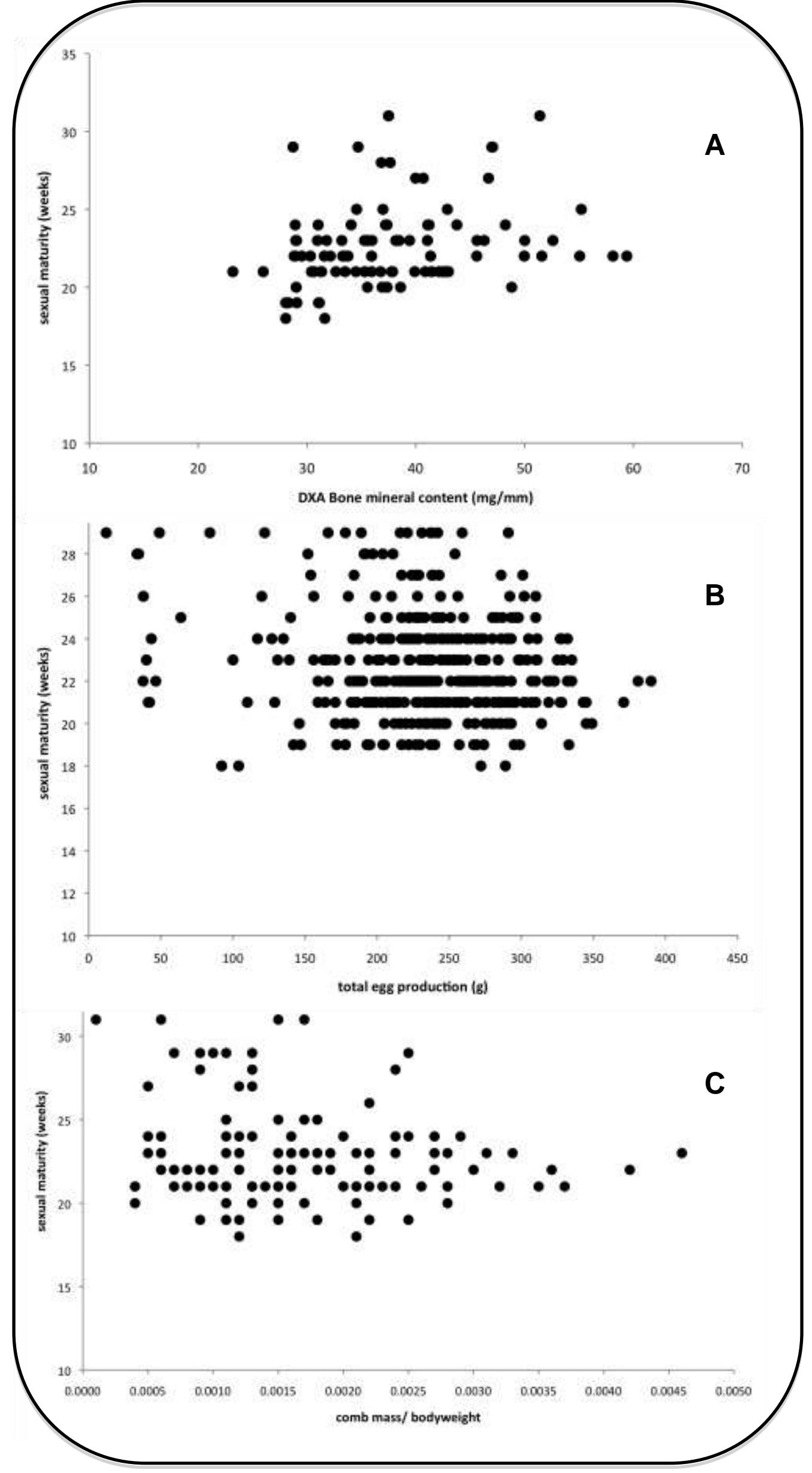




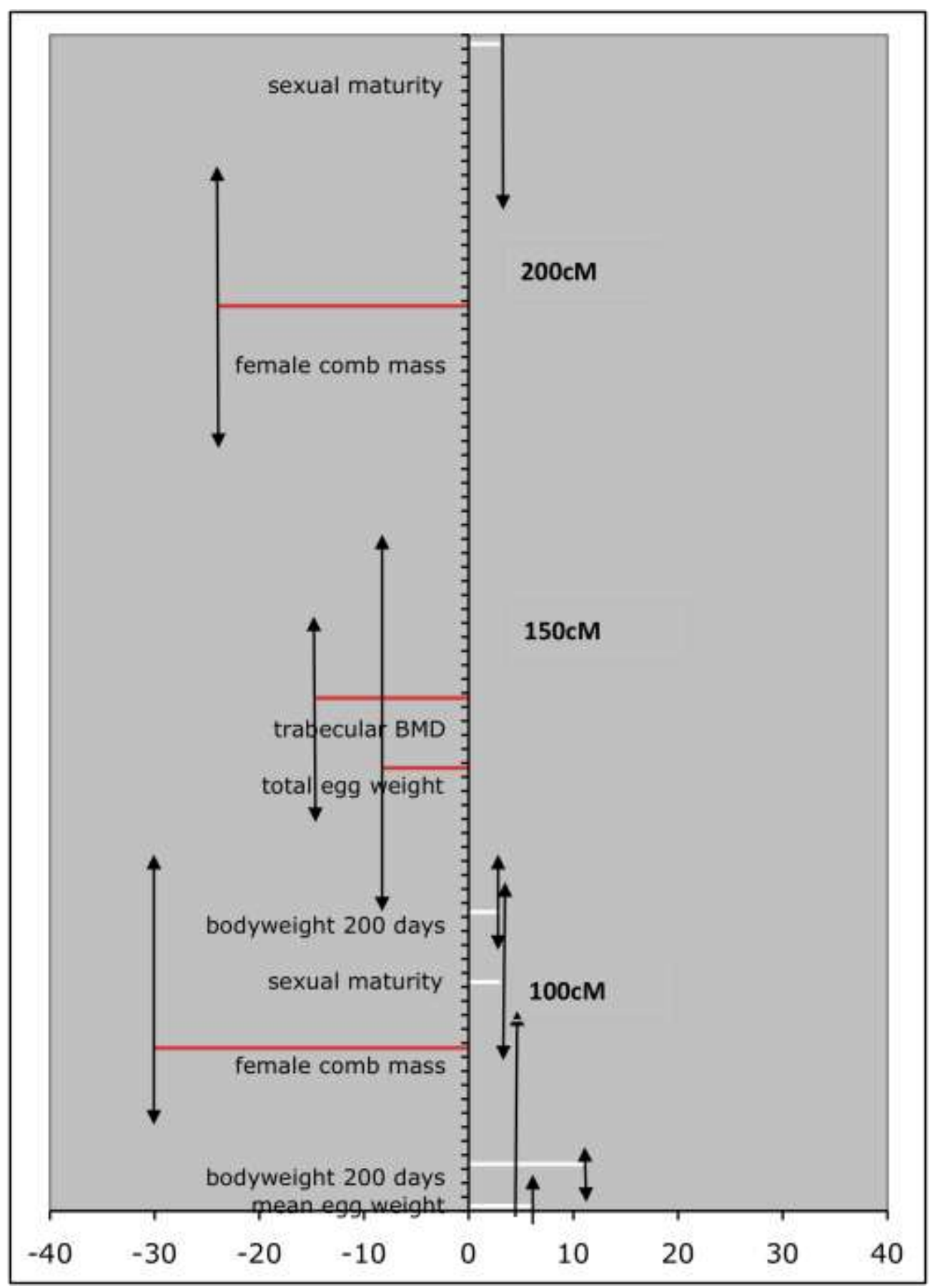




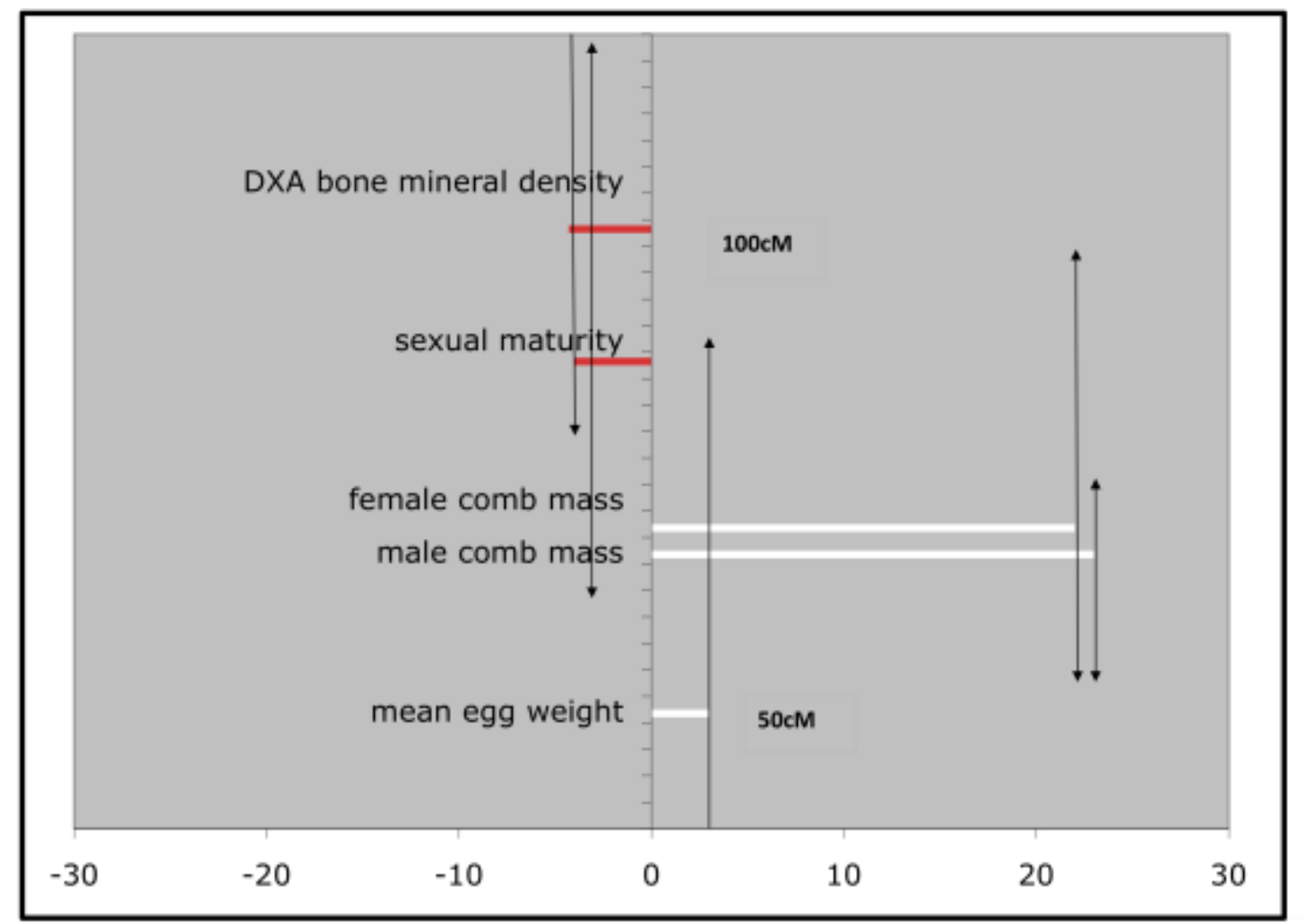




\section{REFERENCES}

Bullock J.; Hall J. C., 1968: Effect of steroid esters on comb growth. Federation Proceedings, 27623.

Carroll S. B.; Grenier J. K.; Weatherbee S. D., 2005: From DNA to Diversity. Blackwell, Oxford.

Cransberg P. H.; Parkinson G. B.; Wilson S.; Thorp B. H., 2001: Sequential studies of skeletal calcium reserves and structural bone volumes in a commercial layer flock. Br Poultry Sci, 260-265.

Dacke C. G.; Arkle S.; Cook D. J.; Wormstone I. M.; Jones S.; Zaidi M.; Bascal Z. A., 1993: Medullary bone and avian calcium regulation. J Exp Biol, 184 63-88.

Etches R., 1996: Reproductionin poultry. CAB International, Wallingford, UK.

Greenwood A. W.; Chu. J. P., 1939: ON THE RELATION BETWEEN THYROID AND SEX GLAND FUNCTIONING IN THE BROWN LEGHORN FOWL. Experimental Physiology, 29 111-119.

Hulet C.; Wiggins E.; Ercanbrack S., 1969: Estrus in range lambs and its relationship to lifetime reproductive success. Journal of Animal Science, 28246.

Joseph N.; Robinson F.; Renema R.; Thorsteinson K., 2003: Comb growth during sexual maturation in female broiler breeders. Journal of Applied Poultry Research, 12 7-13.

Kerje S.; Carlborg O.; Jacobsson L.; Schutz K.; Hartmann C.; Jensen P.; Andersson L., 2003: The twofold difference in adult size between the red junglefowl and White Leghorn chickens is largely explained by a limited number of QTLs. Animal Genetics, 34 264-274.

Kusuhara S.; Schraer H., 1982: Cytology and autoradiography of estrogeninduced differentiation of avian endosteal cells. Calcified Tissue International, 34 352-358.

Larkin D. M.; Pape G.; Donthu R.; Auvil L.; Welge M.; Lewin H. A., 2009: Breakpoint regions and homologous synteny blocks in chromosomes have different evolutionary histories. Genome Research, 19 770-777.

Morey D., 1994: The early evolution of the domestic dog. American Scientist, 82 336-347.

Parker J. E.; McKenzie F. F.; Kempster H. L., 1942: Development of the testis and combs of White Leghon and New Hampshire cockerels. Poultry Science, $2135-44$.

Perez-Enciso M.; Misztal I., 2004: Qxpak: a versatile mixed model application for genetical genomics and QTL analyses. Bioinformatics, 20 2792-2798.

Pizzari T.; Birkhead T. R., 2000: Female feral fowl eject sperm of subordinate males. Nature, 405787.

Pizzari T.; Cornwallis C. K.; Lovlie H.; Jakobsson S.; Birkhead T. R., 2003: Sophisticated sperm allocation in male fowl. Nature, 426 70-73.

Reynolds S. J.; Mänd R.; Tilgar V., 2004: Calcium supplementation of breeding birds: directions for future research. Ibis, 146 601-614.

Rubin C.-J.; Brändström H.; Wright D.; Kerje S.; Gunnarsson U.; Schutz K.; Fredriksson R.; Jensen P.; Andersson L.; Ohlsson C.; Mallmin H.; Larsson S.; Kindmark A., 2007: Quantitative trait loci for BMD and bone strength in an intercross between domestic and wildtype chickens. Journal of Bone and Mineral Research, 22 375-384. 
Schutz K.; Kerje S.; Carlborg O.; Jacobsson L.; Andersson L.; Jensen P., 2002: QTL analysis of a red junglefowl $\mathrm{x}$ White Leghorn intercross reveals trade-off in resource allocation between behavior and production traits. Behavior Genetics, 32 423-433.

Seaton G.; Haley C. S.; Knott S. A.; Kearsey M. J.; Visscher P. M., 2002: QTL Express: mapping quantitative trait lociin simple and complex pedigrees. Bioinformatics, 18 339-340.

Tchernov E.; Horwitz L. K., 1991: Body size diminution under domestication: Unconscious selection in primeval domesticates. Journal of Anthropological Archaeology, 10 54-75.

Wright D.; Kerje S.; Brändström H.; Schütz K.; Kindmark A.; Andersson L.; Jensen P.; Pizzari T., 2008: The genetic architecture of a female sexual ornament. Evolution, 62 86-98.

Wright D.; Kerje S.; Lundström K.; Babol J.; Schutz K.; Jensen P.; Andersson L., 2006: Quantitative trait loci analysis of egg and meat production traits in a red junglefowl x White Leghorn cross. Animal Genetics, 37 529-534.

Zuk M.; Thornhill R.; Ligon J. D.; Johnson K.; Austad S.; Ligon S. H.; Thornhill N. W.; Costin C., 1990: The role of male ornaments and courtship behaviour in female mate choice of red junglefowl. American Naturalist, 136459 473. 